\title{
Electrospinning-Enabled Si/C Nanofibers with Dual Modification as Anode Materials for High-Performance Lithium-Ion Batteries
}

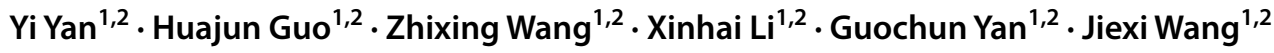

Received: 19 March 2020 / Revised: 26 April 2020 / Published online: 15 June 2020

(C) The Chinese Society for Metals (CSM) and Springer-Verlag GmbH Germany, part of Springer Nature 2020

\begin{abstract}
In this work, silicon@ reduced graphene oxide/pyrolytic carbon nanofibers ( $\mathrm{Si} @ \mathrm{RGO} / \mathrm{C} \mathrm{NFs}$ ) composite with double modified layer is prepared through electrospinning, stabilization and carbonization. In this composite, polyethylene oxide-polypropylene oxide-polyethylene oxide (P123, a non-ionic surfactant) is introduced as the dispersant, which can make silicon nanoparticles evenly dispersed in electrospinning solution to prevent it from agglomeration. Graphene modified layer can buffer the volumetric expansion of silicon nanoparticles, prevent direct contact between silicon and electrolyte as well as enhance the electrical conductivity. Moreover, carbon fibers synthesized by electrospinning can encapsulate silicon@ graphene composite internally to form a double modified layer. This composite with double modified layer can further alleviate the volume change of silicon nanoparticles and avoid direct contact between silicon and electrolyte to form a stable interface. Owing to the above-mentioned merits, the $\mathrm{Si} @ \mathrm{RGO} / \mathrm{C}$ NFs composite exhibits excellent cyclic stability and superior rate performance. Particularly, it maintains a specific capacity of $929 \mathrm{~mA} \mathrm{~h} \mathrm{~g}^{-1}$ with the retention ratio of $83.1 \%$ after 100 cycles at $0.5 \mathrm{~A} \mathrm{~g}^{-1}$ and delivers an outstanding rate capability of $1003 \mathrm{~mA} \mathrm{~h} \mathrm{~g}^{-1}$ at $2 \mathrm{~A} \mathrm{~g}^{-1}$.
\end{abstract}

Keywords Lithium-ion batteries $\cdot$ Silicon/carbon composite $\cdot$ Surface modification $\cdot$ Graphene $\cdot$ Electrospinning

\section{Introduction}

The emergence of lithium-ion batteries (LIBs) has significantly extended the application scope of portable devices, flexible electronics, plug-in electric vehicles and grid-scale energy storage systems by developing electrode materials with high capacity, low cost, long cycle life and excellent rate performance [1-3]. Recently, researches on electrode materials of LIBs have become more extensive, and the performance of electrodes tends to be more mature and stable

Available online at http://link.springer.com/journal/40195.

Electronic supplementary material The online version of this article (https://doi.org/10.1007/s40195-020-01087-z) contains supplementary material, which is available to authorized users.

Jiexi Wang

wangjiexikeen@csu.edu.cn

1 School of Metallurgy and Environment, Central South University, Changsha 410083, China

2 Engineering Research Center of the Ministry of Education for Advanced Battery Materials, Central South University, Changsha 410083, China
[4-10]. However, the demand for thinner electronic equipment and the need of society for electric vehicles urgently require LIBs with higher energy density. This has led to the development of anode materials with higher capacity and better performance. Due to the extremely high theoretical specific capacity ( $3579 \mathrm{~mA} \mathrm{~h} \mathrm{~g}^{-1}$ ), low lithium alloying potential $(0.4 \mathrm{~V})$, abundant reserves and low price, silicon is regarded as one of the most promising anode materials that can replace the commercial graphite [11-14]. However, due to its poor electronic conductivity and serious volume expansion $(\sim 320 \%)$ in the process of lithiation and delithiation, the capacity of silicon anodes is drastically attenuated and the rate performance is poor $[15,16]$. Surface modification with carbon materials and preparation of nanomaterials are proved to be effective methods to enhance the cycle stability and rate performance of silicon anodes by providing volume buffer and improving the conductivity of active materials [17-23]. However, silicon anodes have a significant volume change during charge and discharge process, leading to the rupture of surface-modified singlelayer carbon in the lithium alloying process. As a result, its modification effect is lost. 
At present, electrospinning method has been extensively used to prepare various electrode materials of LIBs due to its superiority of the simple production process and ability for preparing fibers with uniform diameters [24-26]. Particularly, nanoscale active materials can be uniformly dispersed in polymer solution, and polymer fibers produced by electrospinning method can be converted to carbon fibers after heat treatment [27-29]. Therefore, nanosized polymer fibers containing active materials can be prepared by adjusting the electrospinning parameters, and then the carbon fibers including active materials can be obtained through stabilization and carbonization. Recent works have shown that electrospinning method has been used in the preparation of many silicon-based anodes. Ji et al. [30] investigated a silicon/carbon nanofibers anode by electrospinning method, and the composite can maintain a capacity of $720 \mathrm{~mA} \mathrm{~h} \mathrm{~g}^{-1}$ after 100 cycles. Although researchers have done a lot of studies in the field of preparing silicon/carbon composites by electrospinning, it is still urgent to solve the agglomeration problem of silicon particles in solution that results in the capacity decline of the prepared composites. Researchers have also come a long way from inquiries into this problem. Wang et al. [31] reported a uniform silicon nanoparticle/ porous carbon nanofibers hybrid toward free-standing highperformance anodes for lithium-ion batteries by adding dispersant F127. The addition of dispersant enabled more silicon nanoparticles to be uniformly wrapped in the polymer fiber, which improved the cyclic stability of material to a certain extent. However, the capacity attenuation of this $\mathrm{Si} / \mathrm{C}$ composite was still large. This was due to the fact that the single carbon layer cannot suppress the loss of electrical contact between active materials and collector completely owing to the huge volume change of silicon in the charge and discharge process as increasing the silicon loading. Tao et al. [32] prepared a self-supporting silicon/graphene nanocomposite film which showed much higher reversible discharge capacity and a better cycle stability than pure nanosized silicon particles as well as the graphene. Such enhancement could be attributed to the graphene matrix, which offered an electrically conductive channel and a flexible mechanical support for strain release.

Based on this, we propose to build a buffer for the volume expansion of silicon nanoparticles with double modified layer of graphene and carbon fibers. Dispersants P123 (polyethylene oxide-polypropylene oxide-polyethylene oxide, a non-ionic surfactant) is used in electrospinning procedure to further disperse silicon nanoparticles evenly in the polymer solution. Distinct from previous reports, the silicon/carbon nanofibers composite with dual modification we prepared involves (1) adding dispersant P123 that can volatilize completely at about $300^{\circ} \mathrm{C}$ without producing impurities [33], so that can make silicon nanoparticles dispersed better in electrospinning solution without introducing any impurities;
(2) preparing silicon@graphene oxide composite with graphene modified layer by agitation and ultrasonic dispersion; (3) manufacturing silicon@ reduced graphene oxide/carbon nanofibers composite with dual modification of graphene and carbon fibers by electrospinning and heat treatment.

\section{Experimental}

\subsection{Synthesis of Si@GO Composite}

Firstly, $0.1 \mathrm{~g}$ graphene oxide (GO) was dispersed in $100 \mathrm{~mL}$ deionized water. Then $1.0 \mathrm{~g}$ silicon nanoparticles (Si NPs) was added with stirring and ultrasonic shaking. After that, the suspension was stirred in the oil bath of $80^{\circ} \mathrm{C}$ for $12 \mathrm{~h}$ until the deionized water evaporated completely. The silicon nanoparticles with graphene modified layer were produced and named as $\mathrm{Si} @ \mathrm{GO}$ composite.

\subsection{Synthesis of Si@RGO/C NFs}

$0.55 \mathrm{~g} \mathrm{Si} @ \mathrm{GO}$ composite, $1 \mathrm{~g}$ polyacrylonitrile (PAN, M.W $150000)$ and $0.25 \mathrm{~g}$ P123 were added into $10 \mathrm{~mL}$ dimethylformamide (DMF), followed by stirring for $6 \mathrm{~h}$ at $50{ }^{\circ} \mathrm{C}$. After that, the as-prepared solution was poured into a disposable syringe with a uniaxial spinneret jet (needle) of No. 21 . Positive (+) and negative (-, ground) voltages were applied between the syringe needle and plate receiver, respectively. The injection speed, translation speed, translation distance and spinning distance were set at $0.03 \mathrm{~mm} \mathrm{~min}^{-1}$, $50 \mathrm{~mm} \mathrm{~min}{ }^{-1}, 100 \mathrm{~mm}$ and $12 \mathrm{~cm}$, respectively. The collected silicon@graphene oxide/polyacrylonitrile nanofiber ( $\mathrm{Si} @ \mathrm{GO} / \mathrm{PAN} \mathrm{NFs}$ ) composite was firstly heated to $280{ }^{\circ} \mathrm{C}$ at a rate of $2{ }^{\circ} \mathrm{C} \mathrm{min}^{-1}$ and held for $1 \mathrm{~h}$ for stabilization. Then the silicon@ reduced graphene oxide/carbon nanofiber ( $\mathrm{Si} @$ $\mathrm{RGO} / \mathrm{C}$ NFs) composite was obtained by being heated to $725^{\circ} \mathrm{C}$ at a rate of $3{ }^{\circ} \mathrm{C} \mathrm{min}^{-1}$ for $2.5 \mathrm{~h}$ in a pipe furnace for carbonization. To prevent silicon from being oxidized, both heat treatments were performed in an argon atmosphere. Carbon nanofibers (C NFs) were obtained directly through the same electrospinning and heat treatment process without adding Si NPs and any other materials. Silicon@reduced graphene oxide ( $\mathrm{Si} @ \mathrm{RGO}$ ) composite was obtained with $\mathrm{Si} @ \mathrm{GO}$ composite as the precursor by the same heat treatment as above.

\subsection{Material Characterization}

The structure of Si@RGO/C NFs, Si NPs, C NFs and Si@ RGO composite was investigated by X-ray diffractometer (XRD, Rigaku, TTRIII) using $\mathrm{Cu} K_{\alpha}$ radiation. The morphologies of prepared materials were examined with a JSM-6360LV scanning electron microscope (SEM, JEOL), 
and element distribution of the samples was collected by energy-dispersive X-ray spectroscopy analyzer (EDS, EDXGENESIS). The transmission electron microscope (TEM, Titan G2 60-300, FEI) was utilized to observe the microstructure of the materials. The thermal weightlessness of the materials was analyzed by the SDT650 thermo-gravimetric analyzer (TGA, Waters).

\subsection{Electrochemical Tests}

The Si-based electrodes were fabricated through a uniform slurry casting onto copper foil by mixing active materials ( $\mathrm{Si}$ NPs, C NFs, Si@RGO composite and Si@RGO/C NFs), carbon black and binder (7:2:1 in mass ratio) in deionized water by bench-type homogenizer. In this work, sodium alginate was used as the binder because it can maintain the structural stability of the Si-based electrodes during alloying and dealloying $[34,35]$. The copper foil was placed in a vacuum oven at $60{ }^{\circ} \mathrm{C}$ and dried for $6 \mathrm{~h}$ and then punched into circular disks with a diameter of $12 \mathrm{~mm}$ for fabrication of CR2025 coin cells. The electrolyte was $1 \mathrm{M} \mathrm{LiPF}_{6}$ dissolved in the mixture of EC:DMC $(1: 4, \mathrm{v} / \mathrm{v})$ with $2 \%$ FEC. For half cells, the prepared Si-based electrodes were employed as working electrodes, lithium foil was used as the counter/reference electrode, and glass fiber separator was employed as the separator. The discharge and charge tests were carried out on CT2001A (LAND) and BTS-51 (Neware) battery tester with the voltage range from 0.01 to $2 \mathrm{~V}$ at room temperature. The CHI-660D electrochemical analyzer was applied to perform the cyclic-voltammetry (CV, Chenhua) tests at a scanning rate of $0.1 \mathrm{mV} \mathrm{s}^{-1}$. Electrochemical impedance spectroscopy (EIS) was conducted by CHI-660D at the frequency range of $10^{-2}-10^{5} \mathrm{~Hz}$.

\section{Results and Discussion}

The synthesis process of the $\mathrm{Si} @ \mathrm{RGO} / \mathrm{C}$ NFs is schematically depicted in Fig. 1. Firstly, Si@GO suspension was prepared by mixing GO solution with Si NPs. Then the suspension was ultrasonic oscillating and stirring to obtain Si@GO composite. Next, the obtained $\mathrm{Si} @$ GO composite, dispersant P123 and PAN were added into DMF solution, followed by stirring and ultrasonic oscillation to obtain the Si@GO/PAN spinning solution. Si@GO/PAN NFs film was obtained by electrospinning, and the $\mathrm{Si} @ \mathrm{RGO} / \mathrm{C}$ NFs were gathered by stabilization and carbonization.

Figure 2 lists the XRD patterns of $\mathrm{Si} @ \mathrm{RGO} / \mathrm{C}$ NFs, Si NPs, Si@RGO composite and C NFs. As shown in Fig. 2, the pattern of $\mathrm{Si} @ \mathrm{RGO} / \mathrm{C}$ NFs shows diffraction peaks of $28.4^{\circ}, 47.3^{\circ}, 56.1^{\circ}, 69.1^{\circ}$ and $76.4^{\circ}$ that correspond to (111), (220), (311), (400) and (331) lattice planes of crystalline

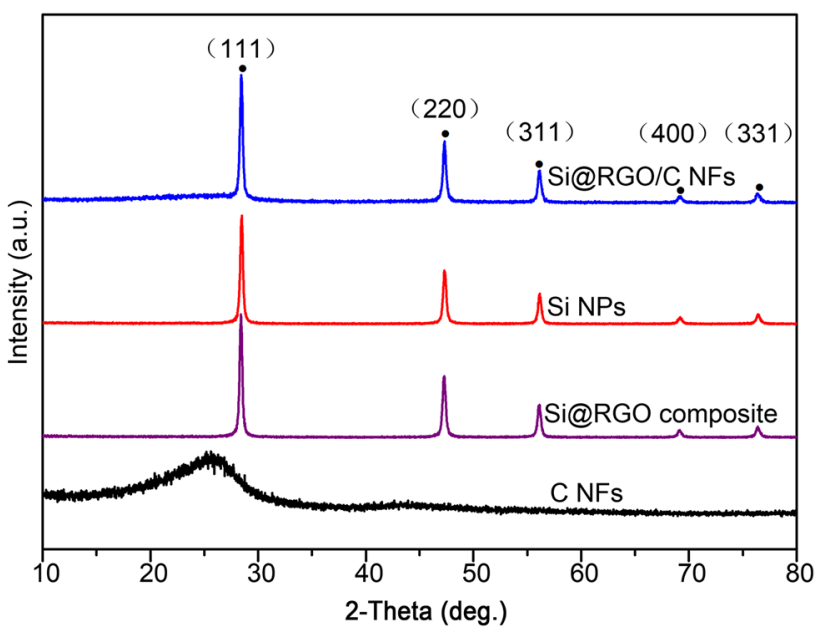

Fig. 2 XRD patterns of Si@RGO/C NFs, Si NPs, Si@RGO composite and C NFs

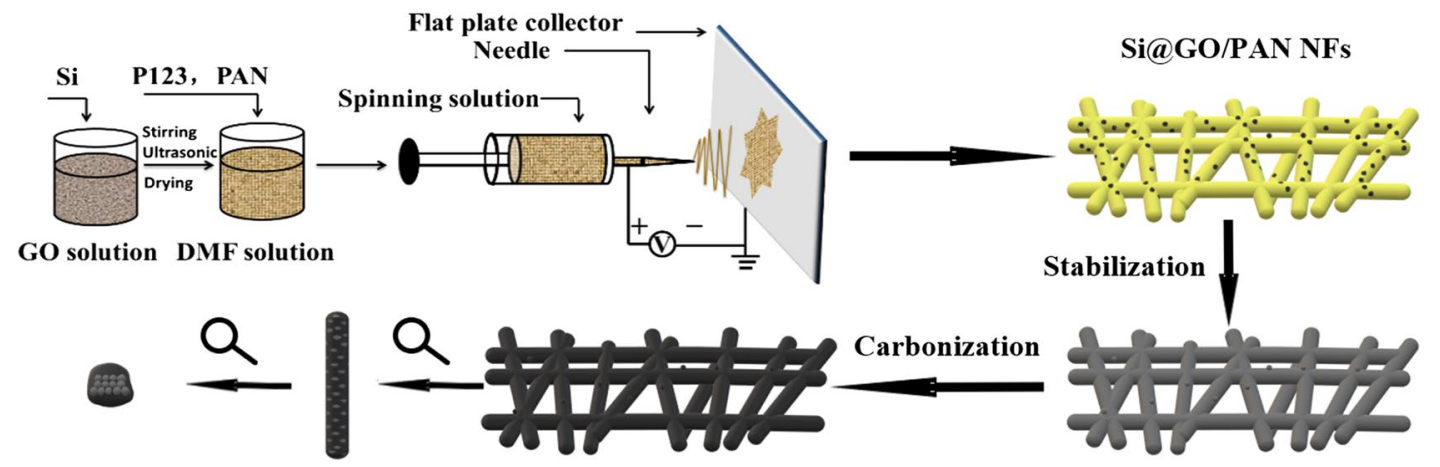

Si@RGO NPs Si@RGO/C NF Si@RGO/C NFs

Si@GO/PAN NFs after stabilization

Fig. 1 Schematic of preparation of $\mathrm{Si} @ \mathrm{RGO} / \mathrm{C}$ NFs 
silicon respectively, conforming to JCPDS No. 75-0589. Meanwhile, in the pattern of Si@RGO/C NFs, the broad diffraction peak appearing at about $25^{\circ}$ can be observed, which corresponds to the (002) lattice plane of amorphous carbon. Therefore, it can be proved that the composite is composed of silicon and amorphous carbon and does not contain impurities.

From the SEM characterization of Si NPs and Si@RGO composite in Fig. 3a, b, a thin film-like substance appears on the surface of Si NPs after graphene modification. Element analyses in Fig. 3c-e reveal that carbon and silicon elements are evenly distributed in the composite. The TEM image (Fig. 3f) shows that $0.3151 \mathrm{~nm}$ lattice fringes appeared in a single particle, and an amorphous layer is presented on the outside of the particle, indicating that the outside of Si NPs is modified with a graphene layer.

The morphologies of Si@GO/PAN NFs and Si@RGO/C NFs are presented in Fig. 4. As demonstrated in Fig. 4a, Si@ GO/PAN NFs composite presents fibers with a diameter of about $150-300 \mathrm{~nm}$ and a rough surface. Specially, there is little accumulation of silicon nanoparticles on the surface of
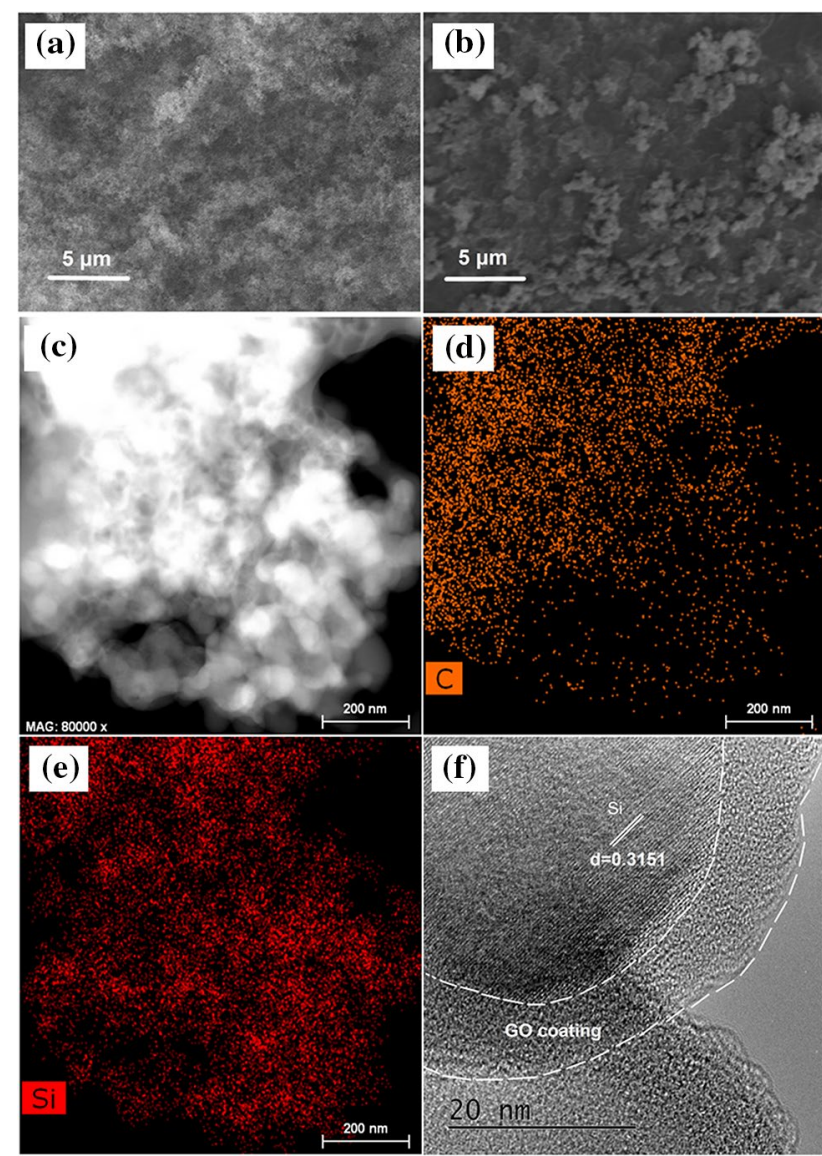

Fig. 3 SEM images of a Si NPs, b Si@RGO composite; c TEM image, $\mathbf{d} \mathrm{C}$ element, e Si element mapping analysis images; $\mathbf{f}$ high resolution TEM image of Si@RGO composite
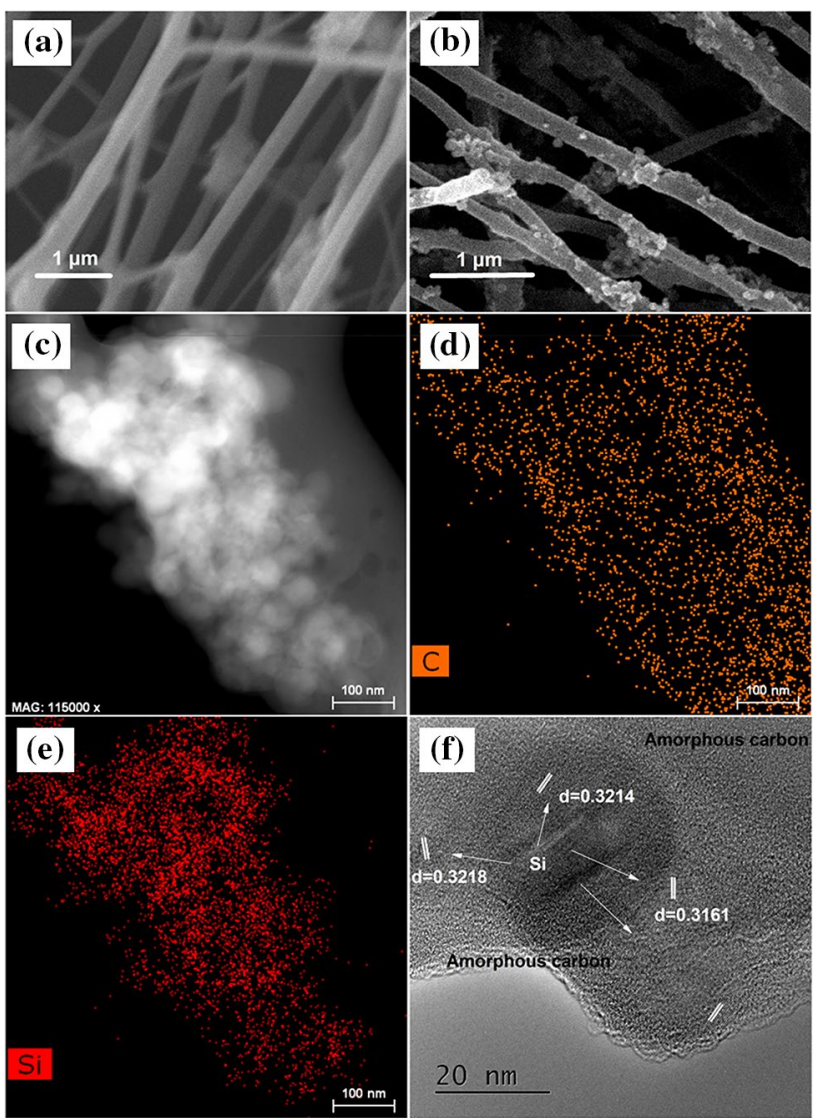

Fig.4 SEM images of a Si@GO/PAN NFs, b Si@RGO/C NFs; c TEM image, $\mathbf{d} \mathrm{C}$ element, e Si element mapping analysis images; $\mathbf{f}$ high resolution TEM image of Si@RGO/C NFs

the fibers as compared to the fibers prepared in many works $[30,31]$, indicating that the $\mathrm{Si} @ \mathrm{GO}$ particles have mostly entered into PAN fibers. As observed in Fig.4b, Si@RGO/C NFs still maintain complete fiber-like morphology after carbonization. Meanwhile, slight connection between fibers can be found. The connected $\mathrm{Si} @ \mathrm{RGO} / \mathrm{C}$ NFs form a continuous carbon framework among the fibers, providing a fast electronic and ionic pathway, and thus enhancing the reaction kinetics. The element mappings (Fig. 4c-e) show that silicon element is evenly distributed in the carbon fibers, forming another carbon modified layer around the Si@RGO particles. Figure S1 presents SEM images of the silicon/carbon nanofibers with and without adding P123 as a dispersant. It can be seen numerous of particles on the surface of the fibers shown in Fig. S1(a) whereas few particle on the surface of the fibers shown in Fig. S1(b). It reveals that the addition of P123 can alleviate the aggregation of Si NPs and can make the particles mostly distributed inside fibers. Because more Si NPs are injected into carbon fibers, the cycle stability and rate performance are improved (Fig. S2). The HR-TEM image in Fig. 4f shows the lattice fringes of 0.3218, 0.3214 and $0.3161 \mathrm{~nm}$, corresponding to the (111) lattice plane of 
silicon. At the surface of Si NPs, amorphous carbon can be found. Therefore, it can be concluded that double modified layer of graphene and amorphous carbon is formed around the silicon nanoparticles.

In order to characterize silicon content in the prepared $\mathrm{Si} @ \mathrm{RGO} / \mathrm{C}$ NFs, the TGA was performed on the prepared composite and Si NPs. The results are shown in Fig. 5. As the temperature rises, silicon reacts with oxygen to form $\mathrm{SiO}_{x}$ and the quality of $\mathrm{Si}$ NPs gradually increases. However, the quality of the $\mathrm{Si} @ \mathrm{RGO} / \mathrm{C}$ NFs composite obviously decreases during the temperature range of $500-650{ }^{\circ} \mathrm{C}$ because of combustion of carbon. After that, it gradually increases, representing the oxidation of silicon. The silicon content of $49.32 \%$ in $\mathrm{Si} @ \mathrm{RGO} / \mathrm{C}$ NFs is calculated by the following formula (1) and thermo-gravimetric data:

$X_{\mathrm{Si} \text { of } \mathrm{Si} @ \mathrm{RGO} / \mathrm{CNFs}}=\frac{W_{\mathrm{Si} @ \mathrm{RGO} / \mathrm{C} \mathrm{NFs} \mathrm{at} 725^{\circ} \mathrm{C}}}{W_{\mathrm{Si} @ \mathrm{RGO} / \mathrm{C} \mathrm{NFs}}} \cdot \frac{W_{\mathrm{Si} \mathrm{NPs}}}{W_{\mathrm{Si} \mathrm{NPs} \text { at } 725^{\circ} \mathrm{C}}}$,

where $X_{\mathrm{Si} \text { of } \mathrm{Si} @ \mathrm{RGO} / \mathrm{C} \text { NFs }}$ is the mass percentage of silicon in $\mathrm{Si} @ \mathrm{RGO} / \mathrm{C} \mathrm{NFs}, W_{\mathrm{Si} @ \mathrm{RGO} / \mathrm{C} \mathrm{NFs}}$ is the initial mass of $\mathrm{Si} @ \mathrm{RGO} / \mathrm{C} \mathrm{NFs}, W_{\mathrm{Si} @ \mathrm{RGO} / \mathrm{C} F \mathrm{~N} \text { at } 725^{\circ} \mathrm{C}}$ is the mass of $\mathrm{Si} @$ $\mathrm{RGO} / \mathrm{C} \mathrm{NFs}$ at $725^{\circ} \mathrm{C}, W_{\mathrm{Si} \mathrm{NPs}}$ is the original mass of $\mathrm{Si}$ NPs, and $W_{\text {Si NPs at }} 725^{\circ} \mathrm{C}$ is the mass of Si NPs at $725^{\circ} \mathrm{C}$.

Figure 6a exhibits the initial charge-discharge curve of Si NPs, Si@RGO composite, C NFs and Si@RGO/C NFs in a voltage window of $0.01-2 \mathrm{~V}$ at $0.1 \mathrm{~A} \mathrm{~g}^{-1}$. As can be seen, $\mathrm{Si} @ \mathrm{RGO} / \mathrm{C}$ NFs show a similar initial discharge and charge curve with Si NP and Si@RGO composite. There are apparently short slope plateaus appearing around $0.75 \mathrm{~V}$ and $0.1 \mathrm{~V}$ for those three Si-contained samples, representing the decomposition of the electrolyte to form a SEI film and lithium ions embedded silicon to form a lithium/silicon alloy phase, respectively. The initial charge specific capacities of Si NPs,Si@RGO composite,Si@RGO/C NFs and

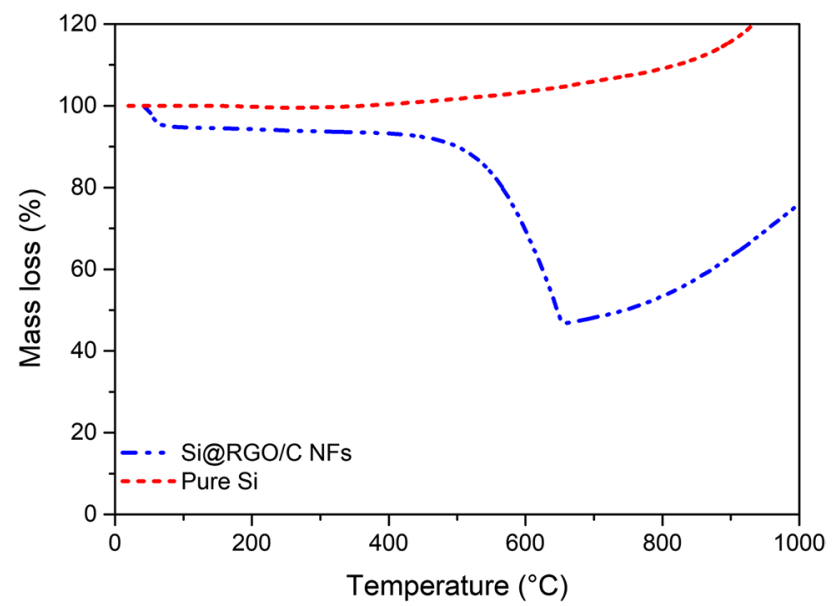

Fig. 5 TG curves of the Si@RGO/C NFs and Si NPs
C NFs are 2751, 2432, 1330, $404 \mathrm{~mA} \mathrm{~h} \mathrm{~g}^{-1}$, with the initial coulombic efficiencies of $81.0 \%, 80.1 \%, 63.7 \%, 44.3 \%$, respectively. It can be found that $\mathrm{Si} @ \mathrm{RGO} / \mathrm{C} \mathrm{NFs}$ composite has lower reversible specific capacity than Si NPs and Si@ RGO composite, because the mass ratio of silicon in the $\mathrm{Si} @$ $\mathrm{RGO} / \mathrm{C}$ NFs is $49.32 \%$ and the reversible capacity of carbon is low. The initial coulombic efficiency of Si@RGO/C NFs is also lower than that of $\mathrm{Si} @ \mathrm{RGO}$ composite and $\mathrm{Si}$ NPs, which is caused by high initial irreversible capacity of amorphous carbon. Figure $6 \mathrm{~b}$ displays the charge-discharge curves of Si@RGO/C NFs at different cycles. The electrode was activated in the first three cycles at $0.1 \mathrm{~A} \mathrm{~g}^{-1}$, and the subsequent cycles were carried out at $0.5 \mathrm{~A} \mathrm{~g}^{-1}$. In Fig. $6 \mathrm{~b}$, the short slope plateaus in $0.75 \mathrm{~V}$ and $0.1 \mathrm{~V}$ disappear in subsequent cycles, exhibiting typical silicon charge-discharge characteristics. Finally, the specific capacity of the $50^{\text {th }}$ cycle is not much different from that of the 10th and 20th cycles, indicating good reversibility of $\mathrm{Si} @ \mathrm{RGO} / \mathrm{C} \mathrm{NFs}$ composite. As shown in Fig. 6c, Si@RGO/C NFs manifest excellent cycling performance with the specific capacity of $929 \mathrm{~mA} \mathrm{~h} \mathrm{~g}^{-1}$ and capacity retention ratio of $83.1 \%$ after 100 cycles. For comparison, the reversible capacity of Si NPs and $\mathrm{Si} @ \mathrm{RGO}$ composite after 100 cycles is $478 \mathrm{~mA} \mathrm{~h} \mathrm{~g}^{-1}$ and $752 \mathrm{~mA} \mathrm{~h} \mathrm{~g}^{-1}$, reflecting $20.5 \%$ and $33.1 \%$ of capacity retention, respectively. By comparing the performance of Si NPs and Si@RGO composite, it can be seen that a very slight amount of graphene addition can increase the cycle stability of Si NPs to some extent. The reason why the cycle performance has not been significantly improved is because graphene and Si NPs are physically bonded and the bonding is liable to fail with the volume change of silicon, resulting in capacity degradation. At the same time, although C NFs have a low capacity of $308 \mathrm{~mA} \mathrm{~h} \mathrm{~g}^{-1}$, the capacity retention is almost $100 \%$, demonstrating excellent structural stability of amorphous carbon. Therefore, the cyclic stability improvement of the composite is attributed to the double modified layer of graphene and carbon fibers in $\mathrm{Si} @ \mathrm{RGO} / \mathrm{C}$ NFs, which can further enable to ease the volume expansion of silicon and reduce the stress concentration. Moreover, rate performances of Si NPs, Si@RGO composite, Si@ $\mathrm{RGO} / \mathrm{C}$ NFs composite and C NFs at 0.1, 0.2, 0.5, 1 and 2 $\mathrm{A} \mathrm{g}^{-1}$ are shown in Fig. 6d. The specific capacity of Si NPs decays quickly as increasing the current density. The Si@ RGO composite shows a relatively higher specific capacity of $1500 \mathrm{~mA} \mathrm{~h} \mathrm{~g}^{-1}$ as compared to Si NPs at $2 \mathrm{~A} \mathrm{~g}^{-1}$. The improved rate performance is related to the existence of graphene which can make a contribution to the improvement of conductivity. Moreover, due to the cooperative effects of graphene and carbon nanofibers dual modification layer, the conductivity and interface stability of $\mathrm{Si} @ \mathrm{RGO} / \mathrm{C}$ NFs are further improved, resulting a specific capacity of $1003 \mathrm{~mA} \mathrm{~h}$ $\mathrm{g}^{-1}$ at $2 \mathrm{~A} \mathrm{~g}^{-1}$. 

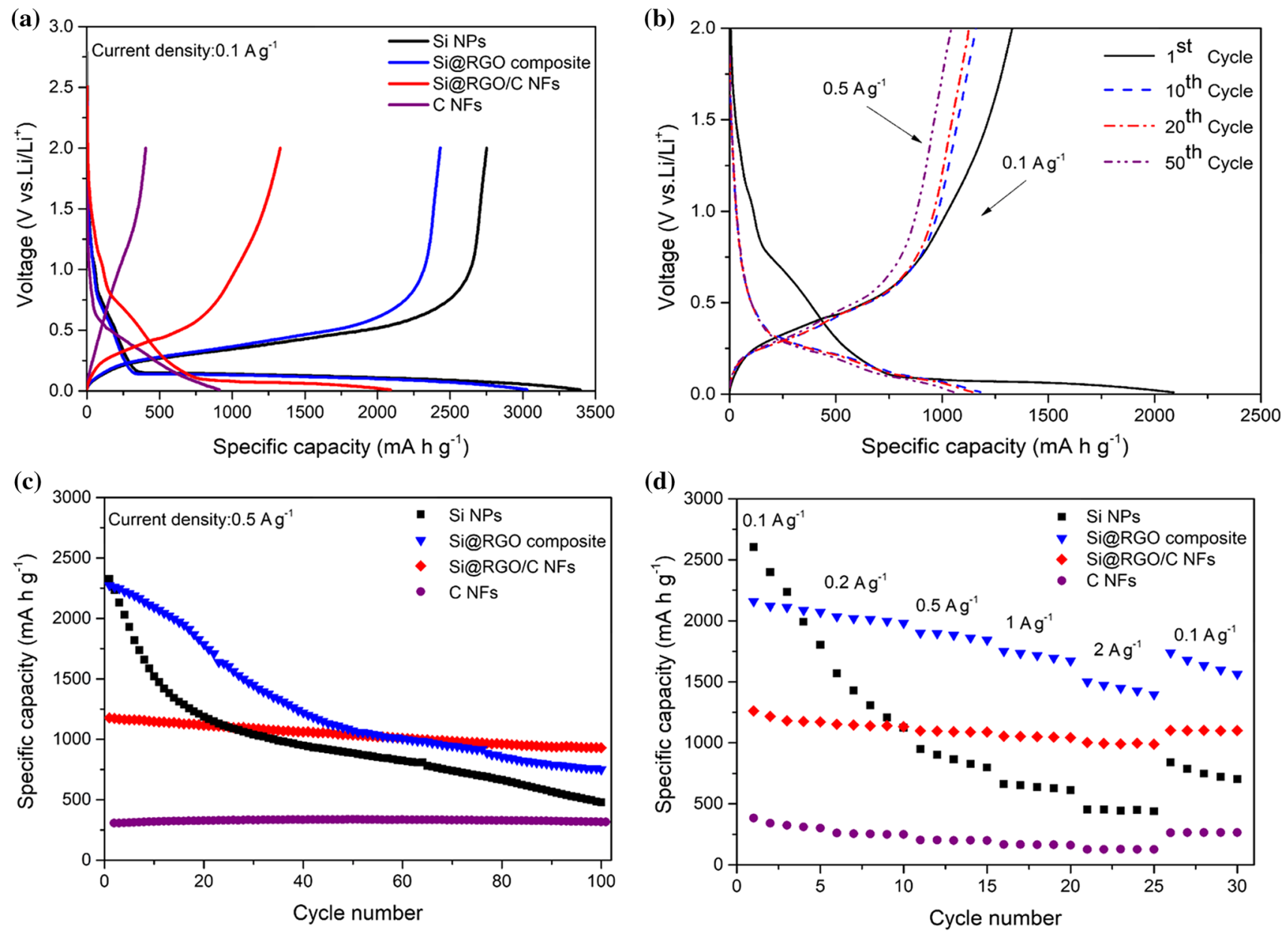

Fig. 6 a Initial discharge-charge curves of Si NPs, Si@RGO composite, Si@RGO/C NFs and C NFs; b charge-discharge curves of Si@RGO/C NFs at different cycles; $\mathbf{c}$ cycling performance; $\boldsymbol{d}$ rate performance of Si NPs, Si@RGO composite, C NFs and Si@RGO/C NFs
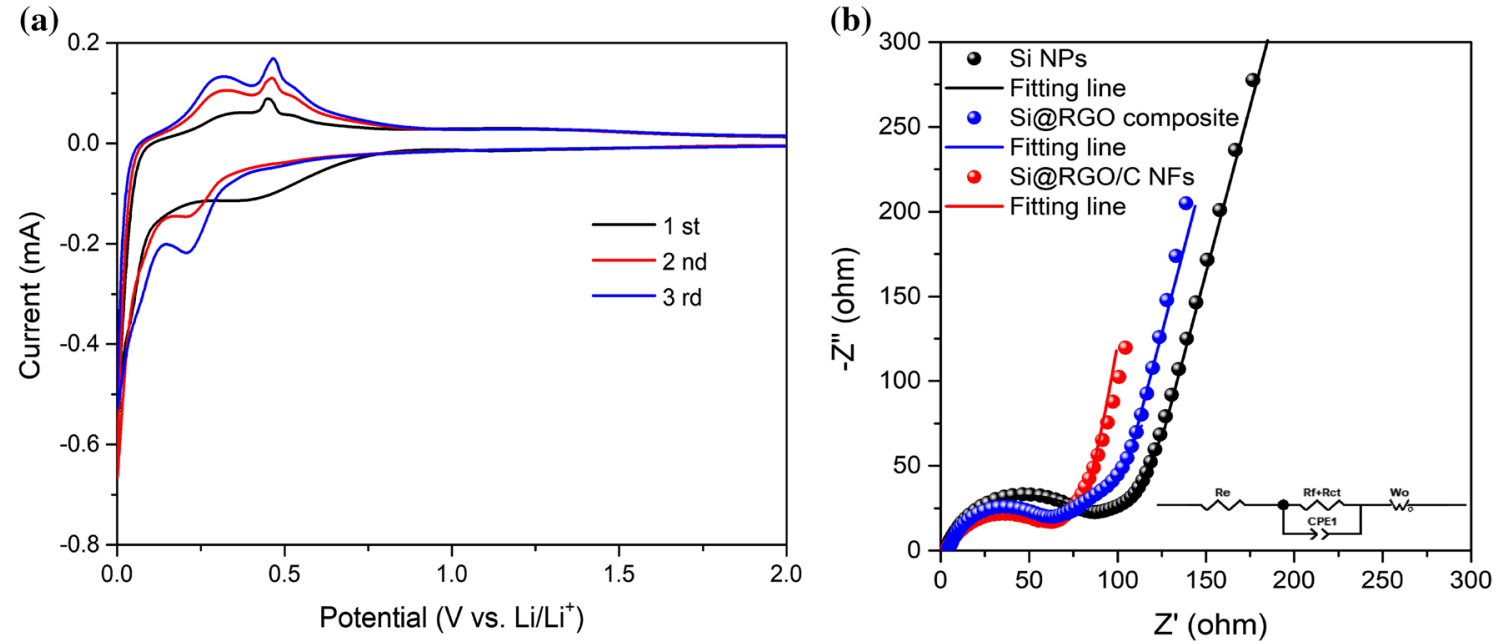

Fig. 7 a The 1st, 2nd and 3rd CV curves; b Nyquist plots and equivalent circuit diagram of Si NPs, Si@RGO and Si@RGO/C NFs 
$\mathrm{CV}$ curves at a scan rate of $0.1 \mathrm{mV} \mathrm{s}^{-1}$ are shown in Fig. 7a. During the reduction process, one cathodic peak at about $0.75 \mathrm{~V}$ is observed in the first cycle but disappeared in succeeding cycles, corresponding to the formation of SEI layer. The other strong cathodic peak at the cutoff voltage of $0.01 \mathrm{~V}$ corresponds to the lithiation reaction of silicon to form $\mathrm{Li}_{x} \mathrm{Si}$ alloy and the lithium ions inserting into the amorphous carbon. The sharp anodic peaks at about $0.38 \mathrm{~V}$ and $0.55 \mathrm{~V}$ are related to the delithiation process of carbon and $\mathrm{Li}_{x} \mathrm{Si}$, respectively, further stressing the appearance of the voltage platform in Fig. $6 \mathrm{~b}$. In the subsequent cycles, the intensity of cathodic peak at $0.25 \mathrm{~V}$, the anodic peaks at $0.38 \mathrm{~V}$ and $0.5 \mathrm{~V}$ is greatly enhanced and the peak area is gradually increased, indicating that the electrode is activated and the lithium storage performance is improved. To further excavate the role of modified layer, EIS measurements of the Si NPs and Si@RGO/C NFs electrodes were carried out before charge-discharge test. As shown in Fig. 7b, the Nyquist plots for Si NPs, Si@GO composite and Si@ RGO/C NFs electrodes contain an intercept, a semicircle and a sloping line, locating at the high-frequency region, intermediate frequency region and the low-frequency region, respectively. The intercept of the starting point of the semicircle on the horizontal axis represents the ohmic impedance $\left(R_{\mathrm{e}}\right)$ of the battery system. $R_{\mathrm{e}}$ is usually small and the gap is not large. The semicircle in the high-frequency region is composed of the mixed impedance region, which includes the interface impedance $\left(R_{\mathrm{f}}\right)$ and charge transfer impedance $\left(R_{\mathrm{ct}}\right)$ of the electrodes. Meanwhile, the diagonal line in the low-frequency region represents the Warburg impedance $\left(Z_{\mathrm{w}}\right)$ formed by the diffusion of lithium ions inside the materials. It can be seen that $\mathrm{Si}$ NPs has the largest $R_{\mathrm{f}}+R_{\mathrm{ct}}$ value, followed by Si@RGO composite, and Si@RGO/C NFs has the lowest value. This indicates that Si@RGO/C NFs with double modified layer has better electron transfer transport capability than bare silicon and $\mathrm{Si} @$ RGO composite. Meantime it is easier to form a stable SEI layer on the surface.

\section{Conclusion}

$\mathrm{Si} @ \mathrm{RGO} / \mathrm{C}$ NFs composite with graphene and carbon fiber double modified layer was successfully synthesized through electrospinning, stabilization, followed by carbonization. The Si@RGO/C NFs electrode retained a specific capacity as high as $929 \mathrm{~mA} \mathrm{~h} \mathrm{~g}^{-1}$ after extended 100 cycles, which was considerably higher than the Si NPs anode. Most importantly, Si@RGO/C NFs had extremely excellent rate performance, showing a specific capacity of $1003 \mathrm{~mA} \mathrm{~h} \mathrm{~g}^{-1}$ at $2 \mathrm{~A} \mathrm{~g}^{-1}$. The superior electrochemical performance of the composite was believed to be associated with the unique architecture as follows: favorable conductivity of the graphene and carbon fibers network, double modified layer of the graphene and carbon fiber on silicon nanoparticles, and good distribution of the $\mathrm{Si} @ \mathrm{GO}$ composite in the carbon fiber by adding P123. This new fabrication strategy could be utilized to prepare lithium-ion battery electrodes and extended to other composite materials.

Acknowledgements This work was financially supported by the National Natural Science Foundation of China (No. 51974370), the Program of Huxiang Young Talents (No. 2019RS2002), the InnovationDriven Project of Central South University (No. 2020CX027), and the Central Universities of Central South University (No. 2018zzts436).

\section{References}

[1] A.R. Dehghani-Sanij, E. Tharumalingam, M. Dusseault, R. Fraser, Renew. Sustain. Energy Rev. 104, 192 (2019)

[2] S. Yun, Y. Zhang, Q. Xu, J. Liu, Y. Qin, Nano Energy 60, 600 (2019)

[3] K. Liu, K. Li, Q. Peng, C. Zhang, Front. Mech. Eng. 14, 47 (2019)

[4] W. Pan, W. Peng, G. Yan, H. Guo, Z. Wang, X. Li, W. Gui, J. Wang, Energy Technol. 6, 2139 (2018)

[5] Y. Lu, X. Hou, L. Miao, L. Li, R. Shi, L. Liu, J. Chen, Angew. Chem. Int. Ed. 58, 7020 (2019)

[6] G. Chen, J. An, Y. Meng, C. Yuan, B. Matthews, F. Dou, L. Shi, Y. Zhou, P. Song, G. Wu, Nano Energy 57, 157 (2019)

[7] F.A. Susai, D. Kovacheva, A. Chakraborty, T. Kravchuk, R. Ravikumar, M. Talianker, J. Grinblat, L. Burstein, Y. Kauffmann, D.T. Major, ACS Appl. Energy Mater. 2, 4521 (2019)

[8] X. Yang, Y.Y. Wang, B.H. Hou, H.J. Liang, X.X. Zhao, H. Fan, G. Wang, X.L. Wu, Acta Metall. Sin. -Engl. Lett. (2020). https:// doi.org/10.1007/s40195-020-01001-7

[9] S. Mohapatra, S.V. Nair, A.K. Rai, Acta Metall. Sin. -Engl. Lett. 31, 164 (2018)

[10] S. Liang, X. Wang, Y. Xia, S. Xia, E. Metwalli, B. Qiu, Q. Ji, S. Yin, S. Xie, K. Fang, L. Zheng, M. Wang, X. Zou, R. Li, Z. Liu, J. Zhu, P.M. Buschbaum, Y. Cheng, Acta Metall. Sin. -Engl. Lett. 31, 910 (2018)

[11] M. Salah, P. Murphy, C. Hall, C. Francis, R. Kerr, M. Fabretto, J. Power Sources 414, 48 (2019)

[12] Y. Ma, H. Tang, Y. Zhang, Z. Li, X. Zhang, Z. Tang, J. Alloys Compd. 704, 599 (2017)

[13] Y. Jin, Y. Tan, X. Hu, B. Zhu, Q. Zheng, Z. Zhang, G. Zhu, Q. Yu, Z. Jin, J. Zhu, ACS Appl. Mater. Interfaces 9, 18 (2017)

[14] S. Chen, Z. Chen, Y. Luo, M. Xia, C. Cao, Nanotechnology 28, 165404 (2017)

[15] M. Ashuri, Q. He, L.L. Shaw, Nanoscale 8, 74 (2016)

[16] A. Casimir, H. Zhang, O. Ogoke, J.C. Amine, J. Lu, G. Wu, Nano Energy 27, 359 (2016)

[17] H. Liu, Z. Shan, W. Huang, D. Wang, Z. Lin, Z. Cao, P. Chen, S. Meng, L. Chen, ACS Appl. Mater. Interfaces 10, 4715 (2018)

[18] M. Wang, G. Wang, S. Wang, J. Zhang, J. Wang, W. Zhong, F. Tang, Z. Yang, J. Zheng, X. Li, Chem. Eng. J. 356, 895 (2019)

[19] G.N. Yushin, I. Luzinov, B. Zdyrko, A. Magasinski, U.S. Patent No. 10,283,759, 7 May 2019

[20] H. Cho, K. Kim, C.M. Park, G. Jeong, J. Power Sources 410, 25 (2019)

[21] P. Li, J. Hwang, Y. Sun, ACS Nano 13, 2624 (2019)

[22] F. Wang, Z. Hu, L. Mao, J. Mao, J. Power Sources 450, 227692 (2020)

[23] W. Tao, P. Wang, Y. You, K. Park, C. Wang, Y. Li, F. Cao, S. Xin, Nano Res. 12, 1739 (2019) 
[24] W. Wang, Y. Liang, Y. Kang, L. Liu, Z. Xu, X. Tian, W. Mai, H. Fu, H. Lv, K. Teng, Mater. Chem. Phys. 223, 762 (2019)

[25] C. Lv, J. Yang, Y. Peng, X. Duan, J. Ma, Q. Li, T. Wang, Electrochim. Acta 297, 258 (2019)

[26] K. Javed, M. Oolo, N. Savest, A. Krumme, Crit. Rev. Solid State Mater. Sci. 44, 427 (2019)

[27] J. Xue, T. Wu, Y. Dai, Y. Xia, Chem. Rev. 119, 5298 (2019)

[28] L. Zhang, S. Gbewonyo, A. Aboagye, A.D. Kelkar, (William Andrew Publishing, 2019), pp. 867-878

[29] O. Pech, S. Maensiri, J. Alloys Compd. 781, 541 (2019)
[30] L. Ji, X. Zhang, Energy Environ. Sci. 3, 124 (2010)

[31] M. Wang, W. Song, J. Wang, L. Fan, Carbon 82, 337 (2015)

[32] H. Tao, L. Fan, Y. Mei, X. Qu, Electrochem. Commun. 13, 1332 (2011)

[33] C. Wu, M. Lu, H. Chuang, Polymer 46, 5929 (2005)

[34] Z. Wu, J. Yang, B. Yu, B. Shi, C. Zhao, Z. Yu, Rare Met. 38, 832 (2019)

[35] I. Kovalenko, B. Zdyrko, A. Magasinski, B. Hertzberg, Z. Milicev, R. Burtovyy, I. Luzinov, G. Yushin, Science 334, 75 (2007) 